RESIDENT

\& FELLOW

SECTION

Section Editor

Mitchell S.V. Elkind,

MD, MS

Kiran Prasad Maski, MD

Shafali Spurling Jeste, MD

Basil T. Darras, MD

Address correspondence and reprint requests to Dr. Kiran Prasad Maski, Department of Neurology, Children's Hospital Boston, 300 Longwood Ave., Boston, MA 02116

kiran.prasad@childrens.harvard.edu

Child Neurology:

\title{
Past, present, and future
}

\author{
Part 2: Present training structure
}

Since its inception 40 years ago, the field of child neurology has continued to expand both in volume and in scope, as discussed in part 1 of this 3-part series. ${ }^{1}$ This article describes the current state of the field, residency training, and the accreditation structure, and discusses how child neurology training must evolve to meet growing demands in clinical practice and research.

STATE OF THE FIELD The wave of knowledge in basic and clinical neurosciences has advanced our understanding of etiology and pathophysiology of childhood neurologic disorders, which has facilitated our ability to diagnose, manage, and prevent both rare and common disorders. Specifically, developments in neurochemistry, genetics, and metabolism have rapidly generated new information about disease processes. In addition, progress in neuroradiology, neurophysiology, and molecular genetics have provided child neurologists with remarkable diagnostic tools. The purview of child neurology has now widened to encompass areas of genetics, behavior, metabolism, sleep medicine, neurovascular diseases, neurooncology, and neuroimmunology, in addition to the more traditional fields of epilepsy, neuromuscular and neurodegenerative disorders, and neonatal neurology.

While this represents an exciting time to be a child neurologist, such expansion in the scope of the field requires a dynamic workforce. According to the Workforce Task Force of the American Academy of Neurology, there were a total of 1,080 active child neurologists in 1998, which translated to 819 full-time-equivalent patient care child neurologists. ${ }^{2}$ Based on the supply model of the Bureau of Health Professions, the Task Force found that staffing was $20 \%$ below the demand for child neurology services, a shortage projected to remain unchanged through 2020. Given this need for increased quantity and quality of child neurologists, scrutiny has fallen on our current child neurology training system.

CURRENT CLINICAL TRAINING STRUCTURE In the 2008-2009 academic year, there were 69 accred- ited child neurology programs in the United States, with 290 approved residency positions. ${ }^{3}$ The Accreditation Council for Graduate Medical Education (ACGME) offers 3 pathways to achieve Certification in Neurology with Special Qualification in Child Neurology: 1) 2 years of general pediatric training and 3 years of neurology training ( 1 year of adult neurology and 2 years of child neurology); 2) 1 year of internal medicine, 1 year of general pediatrics, and 3 years of neurology training; 3) 1 year of pediatrics, 1 year of basic neuroscience research, and 3 years of neurology training. While the majority of trainees choose the first track, the latter 2 tracks have been added to encourage adult neurologists who want to join child neurology training late and to attract students with a research focus. The ACGME requires that the 3-year child neurology training consist of 1 year adult clinical neurology, 1 year of clinical child neurology, and 1 year that is deemed "flexible" in which experiences in neurophysiology, neuropathology, neuroradiology, neuroophthalmology, psychiatry, rehabilitation, neurosurgery, basic sciences, and neurodevelopment are promoted.

While the overall structure of residency programs has not changed much in 50 years, the ACGME and Neurology Residency Review Committee (NRRC) now specify certain clinical requirements, including 4 full months of child neurology outpatient experience (including continuity clinic time), experience in clinical neurosurgery, 1 month of clinical child and adolescent psychiatry, and at least 2 months of experience in a basic neuroscience field (appendix). As evident from the described requirements, child neurology residency training is clinically demanding, with little time directed toward research training. Consequently, some have expressed concern about the declining role of the child neurologist as physician-investigator, especially in a time of rapid expansion of the field, newly available technologies, and increasing complexity of patient management. ${ }^{4}$ In one study of child neurology trainees, 36 of 58 child neurology programs reported no papers written by

From the Department of Neurology (K.P.M.), Children's Hospital Boston; and Harvard Medical School (S.S.J.), Neuromuscular Program, Department of Neurology (B.T.D.), Children's Hospital Boston, Boston, MA.

Disclosure: Author disclosures are provided at the end of the article. 
residents in 1998, 1999, or 2000.5 ACGME and NRRC promote research skills by requiring residencies to teach basic principles of research as part of the core curriculum but currently do not require trainees to complete a research project.

Training needs to evolve to incorporate time and resources for research by creating a curriculum that systematically teaches research methodology, encourages academic mentorship, and facilitates research funding through federal grants and loan repayment programs.

BOARD CERTIFICATION At the end of training, child neurology residents sit for the American Board of Psychiatry and Neurology (ABPN) board certification examination. Residents who have 2 years of training in general pediatrics can also sit for the American Board of Pediatrics (ABP) examination. For candidates who began neurology residency training on or after July 1, 2005, there is a new 3-part computerized examination, with Part II oral boards eliminated. In lieu of oral boards, residents are now required to undergo an evaluation process during their residency training called the Neurology Examination Exercise or NEX. This evaluation assesses skills in history taking, physical examination, humanism, professionalism, and counseling abilities in various child neurology cases.

In the past, the performance of child neurology residents on Part I of the ABPN examination has been less successful than adult neurology residents, which may be due to the fact that only a fraction of the examination reflects child neurology. In one survey, $61 \%$ of child neurology residents passed Part I and Part II on their first attempts, compared to $78 \%$ of adult neurology residents. ${ }^{6}$ With reattempts at the examination, $88 \%$ of child neurologists and $93 \%$ of adult neurologists achieved Board certification. No data are yet publically available regarding the pass rate of child neurology trainees on the modified ABPN Boards. Nevertheless, such statistics raise the question of whether the current training structure prepares child neurology residents to take a board examination focused on adult neurology content. One could argue that either the child neurology training should be modified to meet the ABPN requirements or, conversely, that a different examination should be created for the child neurology board requirements.

CURRENT CONCERNS, FUTURE DIRECTIONS Certainly, the current state of child neurology faces many challenges. A shortage of child neurologists is projected for the future, while current child neurologists report an increase in referrals compared to other pediatric subspecialists and adult neurologists. ${ }^{7}$ One study found that $90 \%$ of general pediatricians believed that the number of child neurologists in the United States was insufficient and 63\% of these respondents reported a wait of more than 5 weeks for an appointment with a child neurologist. ${ }^{8}$ Data from current training programs do not suggest that this void will be filled by the next generation of trainees. A survey commissioned by the Professors of Child Neurology polled the directors of the 58 pediatric neurology residency programs active between 1997 and 2002 and reported that only 65\% of available child neurology residency positions were filled and an average of $47 \%$ of these positions were filled by international medical graduates who may or may not be allowed to practice in this country after training. ${ }^{5}$ The Child Neurology Match Report shows that 63\% of available residency positions were filled in 2009. ${ }^{9}$

One possible factor for this shortage is income. Most respondents in the Child Neurology Workforce Study reported earnings between $\$ 100,000$ and $\$ 175,000$ per year, with an average annual income of $\$ 149,787$. Compared to reports from the Community Tracking Study, child neurologists earn about $\$ 18,000$ less than other pediatric subspecialists, and about $\$ 22,000$ less than adult neurologists. ${ }^{10}$ Financial debt from lengthy educational training may further discourage potential qualified candidates. Additionally, the duration of the training in itself, which typically requires 5 years, may be a deterrent. The most popular ACGME-approved child neurology training track requires 2 years of general pediatric residency training. Some have questioned the necessity of this 2-year commitment, as not all child neurologists seek ABP board certification. ${ }^{10}$ In comparison, adult neurology training requires only 1 year of internal medicine, with residency complete in 4 years. This extra general pediatric training likely does not enhance trainees' abilities to pass the ABPN Boards and may further discourage residents from pursuing further fellowship training or research opportunities. Finally, the lack of emphasis on research during residency may deter budding physician-scientists from entering this field. A restructuring of the residency program to incorporate formal research training, at least for those interested in academic careers, may attract more students and residents.

HOPE FOR THE FUTURE Despite these concerns, the field of child neurology continues to prosper, as the breadth of cases, neurodiagnostic tools, and therapeutic options improve. New opportunities for residents are available in NRRC-approved subspecialty fellowships, including clinical neurophysiology, neuromuscular medicine, vascular neurology, neurodevelopmental pediatrics, pain management, and now 
sleep medicine. As new information about the developing nervous system emerges, research potential in the field expands. Challenges exist but nearly $90 \%$ of child neurologists continue to report career satisfaction. ${ }^{11}$ Certainly, there is cause for optimism but work is needed to improve child neurology training programs to keep pace with modern clinical and research demands of the field. The future of child neurology training will be further discussed in the final article of this 3-part series.

\section{DISCLOSURE}

Dr. Maski reports no disclosures. Dr. Jeste serves on the editorial board of the Resident and Fellow Section of Neurology ${ }^{\circledR}$. Dr. Darras receives royalties from publishing in $U_{p}$ ToDate; serves as a consultant to and receives speaker honoraria from Genzyme Corporation; and receives research support from PTC Therapeutics, the NIH (NIAMS 2P01 NS040828-6A11 [Co-PI] and NINDS HHSN265200423611C, [PI]), SMA Foundation, the Muscular Dystrophy Foundation, and the New England Research Institutes/SMA Foundation.

\section{APPENDIX}

Child neurology requirements as specified by the Accreditation Council for Graduate Medical Education and the Neurology Residency Review Committee:

1. One year clinical adult neurology

2. One year of training shall be referred to as flexible, and the resident must learn the principles of neurophysiology, neuropathology, neuroradiology, neuroophthalmology, psychiatry, rehabilitation, neurologic surgery, neurodevelopment, and the basic neurosciences

a. Two months of full-time equivalent experience is required of each resident in one or more basic sciences on which clinical child neurology is founded, including neuroanatomy, neural and behavioral development, neuropathology, neurophysiology, neuroimaging, neuropsychology, neurochemistry, neuropharmacology, molecular biology, genetics, immunology, and epidemiology, and statistics

b. One month of full-time equivalent clinical adolescent and child psychiatry is required

c. Three months minimum elective time recommended

3. One year clinical child neurology training

a. Management responsibility for patient care in inpatient, outpatient, and consultation service setting; must have experience in management of pediatric patients with acute neurologic disorders in an intensive care unit and emergency department

b. At least 4 months of full-time outpatient clinical child neurology experience required (including longitudinal/continuity clinic)

\section{REFERENCES}

1. Millichap JJ, Millichap JG. Child neurology: past, present, and future: part 1: history. Neurology 2009;73:e31-e33.

2. Bradley W. Neurology in the next two decades: report of the Workforce Task Force of the American Academy of Neurology. Neurology 2000;54:787-789.

3. Graduate Medical Education Information. Review and Accreditation of Graduate Medical Education programs: Accreditation Council for Graduate Medical Education (official Web site). Available at: www.ACGME.org. Accessed April 25, 2009.

4. Ringel SP, Steiner JF, Vickrey BG, Spencer SS. Training clinical researchers in neurology: we must do better. Neurology 2001;57:388-392.

5. Laureta E, Moshe SL. State of training in child neurology 1997-2002. Neurology 2004;62:864-869.

6. Juul D, Percy AK, Kenton EJ 3rd, Scheiber SC. Board certification in child neurology and neurology: cohort study. J Child Neurol 2005;20:25-27.

7. Werner RM, Polsky D. Comparing the supply of pediatric subspecialists and child neurologists. J Pediatr 2005;146: $20-25$.

8. Bale JF, Currey M, Firth S, Larson R, Executive Committee of the Child Neurology Society. The Child Neurology Workforce Study: pediatrician access and satisfaction. J Pediatr 2009; 154:602-606.

9. Child Neurology Match Report: January 2009. Available at: www.sfmatch.org. Accessed June 1, 2009.

10. Polsky D, Weiner J. Child Neurology Workforce Study: a profile of child neurology: reports from practitioners and trainees: Executive Summary Child Neurology Society. September 2003. Available at: www.childneurologysociety.org. Accessed April 25, 2009.

11. Polsky D, Weiner J, Bale JF Jr, Ashwal S, Painter MJ. Specialty care by child neurologists: a workforce analysis. Neurology 2005;64:942-994. 


\section{Neurology}

Child Neurology: Past, present, and future: Part 2: Present training structure

Kiran Prasad Maski, Shafali Spurling Jeste and Basil T. Darras

Neurology 2010;74;e17-e19

DOI 10.1212/WNL.0b013e3181cef7c0

\section{This information is current as of February 8, 2010}

\section{Updated Information \&} Services

References

Subspecialty Collections

Permissions \& Licensing

Reprints including high resolution figures, can be found at: http://n.neurology.org/content/74/6/e17.full

This article cites 8 articles, 5 of which you can access for free at: http://n.neurology.org/content/74/6/e17.full\#ref-list-1

This article, along with others on similar topics, appears in the following collection(s):

All Education

http://n.neurology.org/cgi/collection/all_education History of Neurology

http://n.neurology.org/cgi/collection/history_of_neurology

Information about reproducing this article in parts (figures,tables) or in its entirety can be found online at:

http://www.neurology.org/about/about_the_journal\#permissions

Information about ordering reprints can be found online:

http://n.neurology.org/subscribers/advertise

Neurology ${ }^{\circledR}$ is the official journal of the American Academy of Neurology. Published continuously since 1951, it is now a weekly with 48 issues per year. Copyright . All rights reserved. Print ISSN: 0028-3878. Online ISSN: 1526-632X.

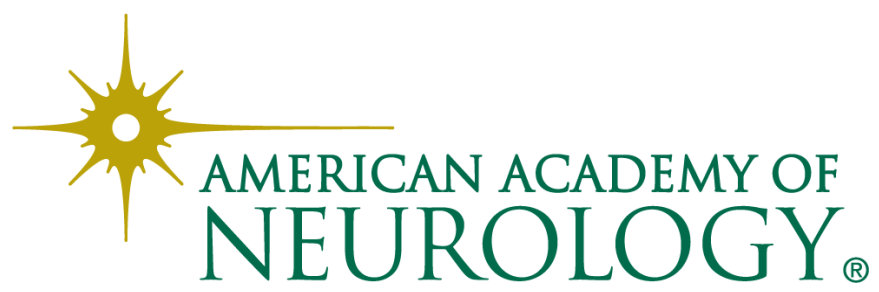

